\title{
Balloon-Guide Catheters Are Needed for Effective Flow Reversal during Mechanical Thrombectomy
}

\author{
(D) Nikoubashman, (DD. Wischer, (D)H.M. Hennemann, (D). Sandmann, (D)T. Sichtermann, (D)F.S. Müschenich, (D) A. Reich, and \\ (D) M. Wiesmann
}

\begin{abstract}
BACKGROUND AND PURPOSE: Blood flow management in the carotid artery during mechanical thrombectomy is crucial for safety and effectiveness. There is an ongoing discussion about whether balloon-guide catheters or large-bore sheaths are needed for effective flow management. We compared general flow characteristics of proximal aspiration through a large-bore sheath and a balloon-guide catheter in a porcine in vivo model.
\end{abstract}

MATERIALS AND METHODS: We investigated blood flow in a porcine common carotid artery with and without aspiration (VacLok syringe and Penumbra pump, Pump MAX) through an 8F-long sheath and an 8F balloon-guide catheter. Blood hemodynamics were assessed via continuous duplex sonography.

RESULTS: Average vessel diameter and baseline blood flow were $4.4 \pm 0.2 \mathrm{~mm}$ and $244 \pm 20 \mathrm{~mL} / \mathrm{min}$, respectively. For the $8 \mathrm{~F}$ sheath, pump aspiration resulted in a significant flow reduction $(225 \pm 25 \mathrm{~mL} / \mathrm{min}, P<.001)$, but with a persisting antegrade stream. Manual aspiration resulted in collapse of the vessel in 2 of 7 measurements and oscillatory flow with antegrade systolic and retrograde diastolic components in the remaining 5 measurements. Net flow was antegrade $(52 \pm 44 \mathrm{~mL} / \mathrm{min})$ in 3 and retrograde $(-95 \pm 52 \mathrm{~mL} / \mathrm{min})$ in the remaining 2 measurements. For balloon-guide catheters, balloon inflation always resulted in flow arrest. Additional pump or manual aspiration resulted in significant flow reversal of $-1100 \pm 230$ and $-468 \pm 46 \mathrm{~mL} / \mathrm{min}$, respectively (both, $P<.001$ ).

CONCLUSIONS: Only balloon-guide catheters allow reliable blood flow arrest and flow reversal in combination with aspiration via syringes or high-flow pump systems. Aspiration through an $8 \mathrm{~F}$ sheath results in either collapse of the vessel or oscillatory flow, which can result in a net antegrade or retrograde stream.

ABBREVIATIONS: $\mathrm{BGC}=$ balloon-guide catheter $\mathrm{CCA}=$ common carotid artery

E ndovascular mechanical thrombectomy has been established as the standard treatment option for acute ischemic stroke caused by large-vessel occlusion. ${ }^{1}$ Even though the basic principle of mechanical thrombectomy is established, actual procedures differ in many ways, ranging from the choice of stent retrievers to the choice of access catheters. ${ }^{2-4}$ Recent clinical studies imply better procedural and clinical outcomes for patients who are treated with balloon-guide catheters (BGCs) compared with other carotid-access catheters such as large-bore sheaths. ${ }^{5,6}$ Zaidat et $\mathrm{al}^{5}$ found, in their analysis of the Systematic Evaluation of Patients Treated With Stroke Devices for Acute Ischemic Stroke (STRA-

Received April 30, 2018; accepted after revision August 13.

From the Departments of Diagnostic and Interventional Neuroradiology (O.N., D.W., H.M.H., J.S., T.S., F.S.M., M.W.) and Neurology (A.R.), RWTH Aachen University Hospital, Aachen, Germany.

Please address correspondence to Omid Nikoubashman, MD, Klinik für Neuroradiologie, Universitätsklinikum Aachen, Pauwelsstr 30, 52074 Aachen, Germany;

e-mail: onikoubashman@ukaachen.de

http://dx.doi.org/10.3174/ajnr.A5829
TIS) Registry data, that BGCs are associated with higher rates of good clinical outcome $(\mathrm{mRS} \leq 2)$, successful revascularization, a trend toward higher rates of complete first-pass revascularization, and a lower number of overall passes. ${ }^{7}$ Because these data are not derived from randomized prospective trials, it is possible that the superiority of BGCs simply reflects their being used by more experienced interventionalists. Nonetheless, it is reasonable that blood flow management in the carotid artery is crucial for safety and effectiveness during mechanical thrombectomy. ${ }^{8}$ It has been shown that thrombectomy maneuvers produce thousands of small clot fragments that may occlude small arterioles and capillaries. ${ }^{4}$ The result can be small infarctions that can have a relevant clinical impact despite being invisible on MR imaging. ${ }^{9,10}$ Hence, flow arrest is important regardless of the specific thrombectomy technique (eg, classic stent-retriever thrombectomy, A Direct Aspiration First Pass Technique [ADAPT], Solumbra, or other techniques). Antegrade blood flow should be reversed during mechanical thrombectomy to prevent embolization of clot frag- 
ments. ${ }^{8}$ This is usually attempted via blood aspiration through an access catheter in the internal carotid artery. There is a variety of access catheters, ranging from small $(5 \mathrm{~F}-7 \mathrm{~F})$ guiding catheters to large-bore sheath catheters $(8 \mathrm{~F})$ and BGCs, but there is no consensus about which access catheter is most suitable. . $^{4,11-13}$

Mechanical thrombectomy is becoming more common, and many interventionalists must decide which technique to choose. Because empiric data are lacking and large randomized prospective studies are needed to resolve this issue from a clinical point of view, we addressed this question with a simple technical approach. To reflect basic principles of flow management in real-life settings, we quantified and compared flow characteristics and aspiration volumes of proximal aspiration through a large-bore sheath and a BGC with both manual and pump aspiration. Because it is practically impossible to quantify blood flow during mechanical thrombectomy in the ICA, let alone in the cerebral arteries, we decided to investigate flow characteristics in an in vivo porcine model.

\section{MATERIALS AND METHODS}

All experiments were performed on 4 female Landrace swine (weight, 50-60 kg) with peri- and intrainterventional management as reported previously. ${ }^{14}$ The experiments were performed in accordance with the German legislation governing animal studies following the "Guide for the Care and Use of Laboratory Animals" (https://grants.nih.gov/grants/olaw/Guide-for-theCare-and-use-of-laboratory-animals.pdf) and the "Directive 2010/63/EU on the Protection of Animals Used for Scientific Purposes" (https://www.researchgate.net/publication/233428185_ DIRECTIVE_201063EU_on_the_protection_of_animals_used_ for_scientific_purposes). Official permission was granted from the governmental animal care and use office, Landesamt für Natur, Umwelt und Verbraucherschutz Nordrhein-Westfalen, Recklinghausen, Germany.

We investigated flow in a porcine common carotid artery (CCA) with and without aspiration through a large-bore sheath and a BGC. We chose the CCA because its diameter is comparable with that of the human ICA. ${ }^{15}$ We adapted flow in the CCA, which has a physiologic blood flow that is twice as high the human ICA blood flow, by injecting blood clots into the subsequent arteries. This procedure was repeated until a blood flow between 200 and $280 \mathrm{~mL} / \mathrm{min}$ was achieved in the target vessel. We assessed blood flow via duplex sonography (LOGIQ S8; GE Healthcare, Milwaukee, Wisconsin) by measuring vessel diameter and flow speed using the built-in software and GraphClick software (Arizona Software, Neuchâtel, Switzerland).

Instead of testing all possible access catheters ranging from $5 \mathrm{~F}$ guide catheters to large-bore sheaths, we chose 1 large-bore sheath and 1 large-bore BGC to investigate flow characteristics in 2 setups that supposedly allow maximum flow control. We used an 8F-long sheath, Shuttle Select (Cook, Bloomington, Indiana; outer diameter, $3 \mathrm{~mm}$; inner diameter, $2.87 \mathrm{~mm}$ ) and an 8F FlowGate II BGC (Concentric Medical, Mountain View, California; outer diameter, $2.7 \mathrm{~mm}$; inner diameter, $2.1 \mathrm{~mm}$ ), which are currently the largest of the most commonly used proximal access catheters. Sheaths and BGCs were introduced through a femoral access and placed 5-7 $\mathrm{cm}$ behind the CCA origin. Blood flow was

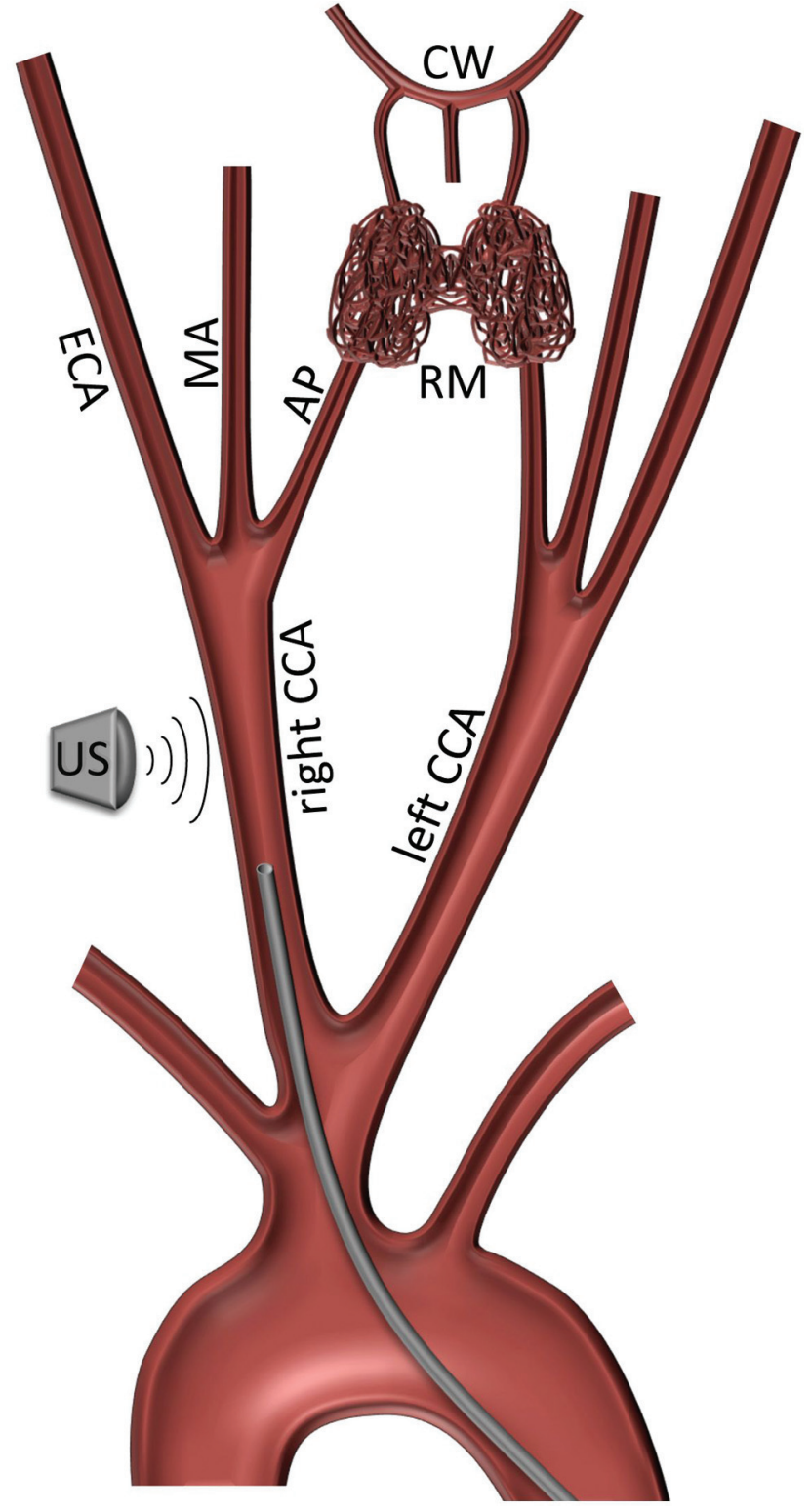

FIG 1. Schematic illustration of the porcine anatomy and the experimental setup. The catheter (thick gray line) is placed in the common carotid artery, which has a diameter comparable with that of the human internal carotid artery. The flow in the CCA was reduced to comparable values by clogging the subsequent vessels. US indicates sonography probe; ECA, external carotid artery; MA, maxillary artery; $A P$, ascending pharyngeal artery; RM, rete mirabile; CW, circle of Willis. Note that swine have a true bovine arch and that the internal carotid arteries arise from the rete mirabile, which is a spongiform conglomerate of blood vessels that serves as a filter for clots.

assessed 7-10 cm distal to the sheath/BGC tips (Fig 1). We did not measure immediately behind the catheter tips to avoid measuring blood flow in areas of turbulent flow. After quantifying the baseline blood flow in the CCA, we quantified blood flow with and without aspiration through the sheath and the inflated BGC. Aspiration was performed manually with a $60-\mathrm{mL}$ VacLok syringe (Merit Medical Systems, South Jordan, Utah) and with a Penumbra pump, Pump MAX (Penumbra, Alameda, California), which is the most common aspiration pump, with the recommended vacuum pressure of $-25.5 \mathrm{Hg}$. All experiments were performed at least 7 times, and all measurements were included in our final 

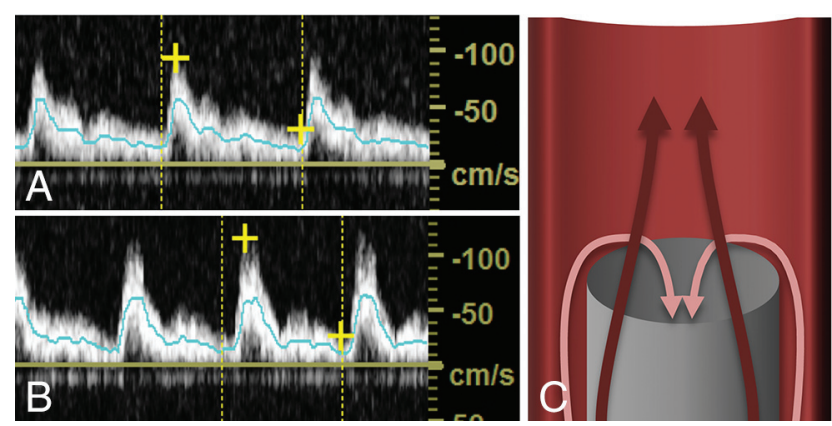

FIG 2. A, Typical sonography blood flow profile in the common carotid artery in our model. $B$, Typical flow profile in the common carotid artery during pump aspiration through an $8 \mathrm{~F}$ sheath. Note that the profile is almost unchanged and flow remains antegrade. $C$, This feature is likely because aspiration results in an additional pressure gradient that mobilizes additional flow from the aortic arch into the CCA along the catheter (C, light arrows), while antegrade flow in the distal CCA is maintained (C, dark arrows).

analysis. Because our experiments resulted in considerable blood loss, not all experiments were repeated in all swine. However, every setup was performed in at least 2 swine to increase the variance. To restrict aspirated blood volume, we performed only 3 aspiration experiments with an inflated BGC as a proof of principle. Blood flow was assessed regularly between experiments to anticipate unnoticed shifts of baseline values.

\section{Statistical Analysis}

Student $t$ tests were used for comparison of flow volumes after testing our data for normal distribution with a Shapiro-Wilk test. $P$ values of an $\alpha$ level of $\leq .05$ were significant. All statistical analyses were performed with SPSS 23 software (IBM, Armonk, New York).

\section{RESULTS}

The average diameter of the CCA and baseline blood flow were $4.4 \pm 0.2 \mathrm{~mm}$ and $244 \pm 20 \mathrm{~mL} / \mathrm{min}$, respectively (Fig 1 ). The $8 \mathrm{~F}$ sheath resulted in an average reduction of vessel diameter and cross-sectional area of $61 \%$ and $37 \%$, respectively, and the sheath did not significantly reduce blood flow $(236 \pm 25 \mathrm{~mL} / \mathrm{min}, P=$ .19). Pump aspiration resulted in a significant flow reduction with a net flow of $225 \pm 25 \mathrm{~mL} / \mathrm{min}(P<.001)$ (Fig 2$)$. However, flow always remained antegrade, and there was no flow arrest or reversal. Manual aspiration through the $8 \mathrm{~F}$ sheath resulted in collapse of the vessel in 2 of 7 measurements. In the remaining 5 measurements, there was an oscillatory flow with antegrade flow in systole and retrograde flow in diastole (Fig 3). Net flow was antegrade $(52 \pm 44 \mathrm{~mL} / \mathrm{min})$ in 3 of 5 measurements and retrograde $(-95 \pm$ $52 \mathrm{~mL} / \mathrm{min}$ ) in the remaining 2 measurements.

The noninflated $8 \mathrm{~F}$ BGC in the CCA led to an average reduction of vessel diameter and cross-sectional area of $61 \%$ and $37 \%$, respectively, and slightly reduced blood flow (from $244 \pm 20$ to $228 \pm 22 \mathrm{~mL} / \mathrm{min}, P=.02$ ). Balloon inflation always resulted in arrest of antegrade flow (Fig 4). Additional pump aspiration and manual aspiration through an inflated BGC resulted in a constant and significant flow reversal with a flow of $-1100 \pm 230$ and $-468 \pm 46 \mathrm{~mL} / \mathrm{min}$, respectively (both, $P<.001$ ) (Fig 4 ). Net flow in the carotid artery was significantly lower when blood was

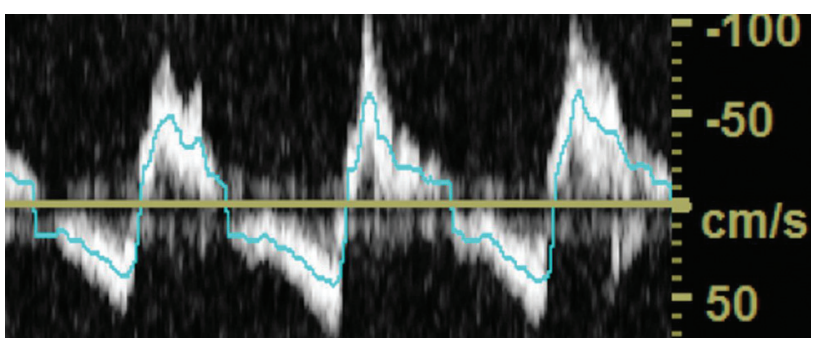

FIG 3. Oscillatory blood flow with antegrade flow in systole and retrograde flow in diastole after manual aspiration through the $8 \mathrm{~F}$ sheath.

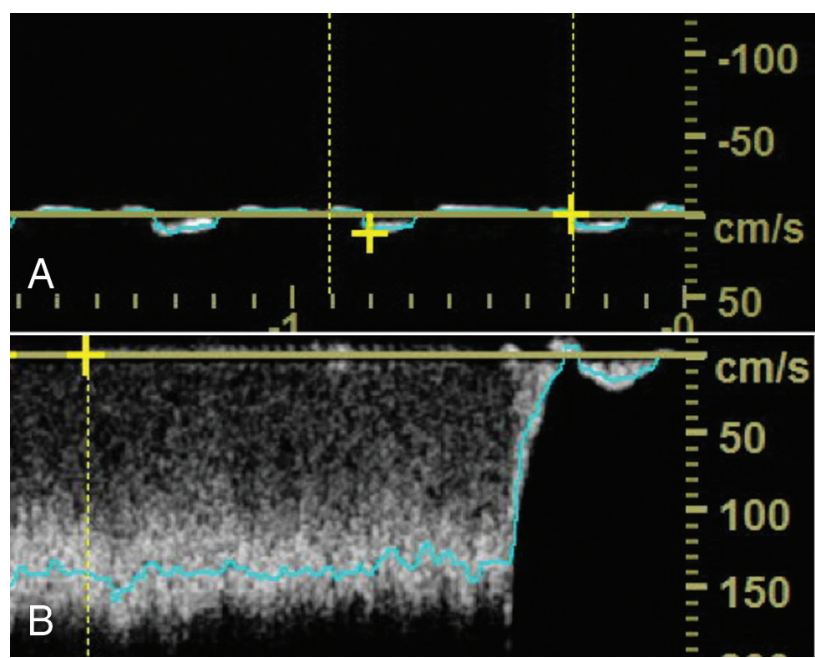

FIG 4. $A$, Balloon inflation results in flow arrest in the CCA. B, Manual aspiration through an inflated BGC results in a constant and significant flow reversal.

aspirated through an inflated BGC compared with the $8 \mathrm{~F}$ sheath, regardless of pump or syringe aspiration (both, $P<.001$ ).

\section{DISCUSSION}

Ever since mechanical stroke treatment has been established as a standard treatment technique, the focus of neurointerventional stroke research has shifted to finding the optimal treatment techniques. ${ }^{1,2,4,16-18}$ Proximal aspiration in the ICA to achieve flow reversal has been established as a standard technique for mechanical thrombectomy. In an average patient and without application of a balloon-guide catheter, which restricts antegrade flow, the amount of aspirated blood in the ICA should surpass its normal flow of $240 \mathrm{~mL} / \mathrm{min}$ to achieve reliable flow reversal. ${ }^{19}$ There is an ongoing discussion of whether BGCs or large-bore sheaths are needed for effective flow management. Large-bore sheaths allow aspiration of high-flow volumes up to approximately $1000 \mathrm{~mL} /$ min. ${ }^{20}$ However, the handling of these sheaths is rather complicated because their stiffness necessitates additional guiding catheters for placement. BGCs allow reliable occlusion of the respective artery and consecutive reduction of antegrade flow. However, rather difficult handling and their comparably small inner diameters, which restrict the choice of catheters/devices that can be introduced through the BGC, prevent many interventionalists from using BGCs.

Our results show that the choice of carotid access catheter has in important impact on blood flow in the target vessel. We have

AJNR Am J Neuroradiol 39:2077-81 Nov 2018 www.ajnr.org 
found that only BGCs allow reliable flow arrest in our in vivo porcine model. In a patient, this does not mean that balloon inflation results in arrest of cerebral perfusion because collaterals may maintain cerebral blood flow distal to the occlusion site. As long as the clot is located above the circle of Willis, flow from the posterior and anterior communicating arteries and the ophthalmic artery can sustain the full physiologic flow volume of the ICA and may cause embolization of clot fragments. ${ }^{21}$ Consequently, aspiration of blood through an inflated BGC is necessary for reliable retrograde flow and control of peripheral embolization. Aspiration through the BGC with the syringe and with the Penumbra pump resulted in constant retrograde flow. However, only the syringe achieved high flow that surpassed the required antegrade flow rate of $240 \mathrm{~mL} / \mathrm{min}$ for reliably reverting blood flow at the level of the terminal segment of the internal carotid artery. Therefore, we discourage using the Penumbra pump if flow reversal during mechanical thrombectomy is intended.

Surprisingly, aspiration with large-bore sheaths did not necessarily result in flow arrest or reversal, despite high-aspiration flow volumes. Aspiration through an $8 \mathrm{~F}$ sheath with a syringe or a Penumbra pump results in flow volumes of $\approx 800$ and $\approx 240 \mathrm{~mL} /$ min, respectively. ${ }^{20}$ By simply adding antegrade and retrograde flow, we would have expected a net backward flow of $>500 \mathrm{~mL} /$ min with the syringe and flow arrest with the Penumbra pump. However, aspiration through an $8 \mathrm{~F}$ sheath did not result in reliable flow reversal. At best, there was oscillatory flow with small net backward flow volumes, which would not suffice to reverse blood flow above the circle of Willis. This behavior is likely because aspiration results in an additional pressure gradient that mobilizes additional flow from the aortic arch into the CCA along the catheter while antegrade flow in the ICA is maintained (Fig 2). In the worst-case scenario, aspiration resulted in vessel collapse, which coincides with our clinical experience: During our interventions, we have found that when too much suction is applied, blood cannot be aspirated until the suction is decreased either because the catheter tip has engaged the vessel wall or-as we surmise - the vessel collapsed. Vessel collapse in perfused vessels is mainly due to the Bernoulli effect, which causes the vessel walls to converge during aspiration of high flow volumes. This issue is relevant in clinical practice because it is almost impossible to predict vessel collapse: Many factors such as flow volume, position of the catheter, occlusion site, and the diameter of the vessel and its rigidity have an impact on the applied forces that cause vessel collapse. Given that aspiration with large-bore sheaths did not reliably result in flow arrest or reversal, we discourage using largebore catheters or sheaths for flow arrest in the ICA, regardless of syringe or pump aspiration. Furthermore, we specifically discourage using smaller guiding catheters $(5 \mathrm{~F}-7 \mathrm{~F})$, which are very common because of their easy handling and low cost but face the same issue of insufficient aspiration like the larger sheath tested in our experiment. Notably, even under ideal conditions (perfect vacuum and no external resistors), aspiration flow through a $6 \mathrm{~F}$ catheter with a stent retriever in its lumen does not reach $240 \mathrm{~mL} / \mathrm{min}^{17}$

\section{Limitations}

A major limitation of our study is that it does not allow assessing whether cerebral blood flow above the circle of Willis is reversed.
Such an experiment would need transcranial Doppler measurements in patients during thrombectomy, which is impossible due to the artifacts caused by the microcatheter and stent retriever in place. As an approximation, we estimated the following: Physiologic blood flow in an internal carotid artery is approximately 240 $\mathrm{mL} / \mathrm{min}$. It has been shown that aspiration flow through an $8 \mathrm{~F}$ BGC with pump and syringe aspiration can surpass $350 \mathrm{~mL} / \mathrm{min}$ (pump) and $500 \mathrm{~mL} / \mathrm{min}$ (syringe), which again should be sufficient to allow flow arrest despite collateral flow. Nonetheless, there remains the possibility that collateral flow through the circle of Willis may be enough to maintain antegrade cerebral blood flow despite high-aspiration flow volumes. ${ }^{20}$ Also, due to the nature of our study, we could not investigate whether flow reversal has an effect on clinical outcome, but our results may serve as a foundation for future research that specifically addresses this question. Also, even though the porcine cardiovascular system serves as an excellent model, it may be arguable whether our quantitative results can be translated to patients without restrictions. Nonetheless, because it is impossible to conduct such an experiment in patients the porcine model is the best approximation to real life. ${ }^{22}$ Last, flow volume measurements based on duplex sonography may not always reflect actual flow volumes and are a minor limitation of our study. ${ }^{23}$ However, even if flow volumes are over- or underestimated, our results remain valid on a qualitative level because the direction of flow is unaffected by the measuring method.

\section{CONCLUSIONS}

Only BGCs allow reliable flow reversal and should be used with syringes or high-flow pump systems. Aspiration through an $8 \mathrm{~F}$ sheath in the ICA results in either collapse of the vessel or oscillatory flow with antegrade flow in systole and retrograde flow in diastole, which can result in a net antegrade or retrograde flow.

Disclosures: Martin Wiesmann—UNRELATED: Consultancy: Stryker Neurovascular; Payment for Lectures Including Service on Speakers Bureaus: Bracco, Medtronic, Siemens, Stryker Neurovascular; Payment for Development of Educational Presentations: Abbott, ab medica, Acandis, Bayer HealthCare, Bracco, B. Braun, Codman Neurovascular, Kaneka Pharma Europe, Medtronic, Dahlhausen Medizintechnik, MicroVention, Penumbra, phenox, Philips Healthcare, Route 92, Siemens, Silk Road Medical, St. Jude, Stryker Neurovascular.* *Money paid to the institution.

\section{REFERENCES}

1. Goyal M, Menon BK, van Zwam WH, et al; HERMES collaborators. Endovascular thrombectomy after large-vessel ischaemic stroke: a meta-analysis of individual patient data from five randomised trials. Lancet 2016;387:1723-31 CrossRef Medline

2. Maus V, Behme D, Kabbasch C, et al. Maximizing first-pass complete reperfusion with SAVE. Clin Neuroradiol 2018;28:327-38 CrossRef Medline

3. Turk AS, Frei D, Fiorella D, et al. ADAPT FAST study: a direct aspiration first pass technique for acute stroke thrombectomy. $\mathrm{J} \mathrm{Neu}$ rointerv Surg 2014;6:260-64 CrossRef Medline

4. Chueh JY, Puri AS, Wakhloo AK, et al. Risk of distal embolization with stent retriever thrombectomy and ADAPT. J Neurointerv Surg 2016;8197-202 CrossRef Medline

5. Zaidat O, Liebeskind D, Jahan R, et al. O-005 influence of balloon, conventional, or distal catheters on angiographic and technical outcomes in STRATIS. J Neurointerv Surg 2016;8(Suppl 1):A3.2-4 CrossRef

6. Velasco A, Buerke B, Stracke CP, et al. Comparison of a balloon 
guide catheter and a non-balloon guide catheter for mechanical thrombectomy. Radiology 2016;280:169-76 CrossRef Medline

7. Mueller-Kronast NH, Zaidat OO, Froehler MT, et al. Systematic evaluation of patients treated with neurothrombectomy devices for acute ischemic stroke: primary results of the STRATIS Registry. Stroke 2017;48:2760-68 CrossRef Medline

8. Chueh JY, Kühn AL, Puri AS, et al. Reduction in distal emboli with proximal flow control during mechanical thrombectomy: a quantitative in vitro study. Stroke 2013;44:1396-401 CrossRef Medline

9. Jouvent E, Poupon C, Gray F, et al. Intracortical infarcts in small vessel disease: a combined 7-T postmortem MRI and neuropathological case study in cerebral autosomal-dominant arteriopathy with subcortical infarcts and leukoencephalopathy. Stroke 2011;42: e27-30 CrossRef Medline

10. Shih AY, Blinder P, Tsai PS, et al. The smallest stroke: occlusion of one penetrating vessel leads to infarction and a cognitive deficit. Nat Neurosci 2013;16:55-63 CrossRef Medline

11. Eesa M, Almekhlafi MA, Mitha AP, et al. Manual aspiration thrombectomy through balloon-tipped guide catheter for rapid clot burden reduction in endovascular therapy for ICA L/T occlusion. Neuroradiology 2012;54:1261-65 CrossRef Medline

12. Lally F, Soorani M, Woo T, et al. In vitro experiments of cerebral blood flow during aspiration thrombectomy: potential effects on cerebral perfusion pressure and collateral flow. J Neurointerv Surg 2016;8:969-72 CrossRef Medline

13. Madjidyar J, Hermes J, Freitag-Wolf S, et al. Stent-thrombus interaction and the influence of aspiration on mechanical thrombectomy: evaluation of different stent retrievers in a circulation model. Neuroradiology 2015;57:791-97 CrossRef Medline

14. Nikoubashman O, Pjontek R, Brockmann MA, et al. Retrieval of migrated coils with stent retrievers: an animal study. AJNR Am J Neuroradiol 2015;36:1162-66 CrossRef Medline
15. Mühlenbruch G, Nikoubashman O, Steffen B, et al. Endovascular broad-neck aneurysm creation in a porcine model using a vascular plug. Cardiovasc Intervent Radiol 2013;36:239-44 CrossRef Medline

16. Wiesmann M, Brockmann MA, Heringer S, et al. Active push deployment technique improves stent/vessel-wall interaction in endovascular treatment of acute stroke with stent retrievers. J Neurointerv Surg 2017;9:253-56 CrossRef Medline

17. Nikoubashman O, Alt JP, Nikoubashman A, et al. Optimizing endovascular stroke treatment: removing the microcatheter before clot retrieval with stent-retrievers increases aspiration flow. J Neurointerv Surg 2017;9:459-62 CrossRef Medline

18. Massari F, Henninger N, Lozano JD, et al. ARTS (Aspiration-Retriever Technique for Stroke): initial clinical experience. Interv Neuroradiol 2016;22:325-32 CrossRef Medline

19. Schöning M, Walter J, Scheel P. Estimation of cerebral blood flow through color duplex sonography of the carotid and vertebral arteries in healthy adults. Stroke 1994;25:17-22 CrossRef Medline

20. Nikoubashman O, Wischer D, Hennemann HM, et al. Under pressure: comparison of aspiration techniques for endovascular mechanical thrombectomy. AJNR Am J Neuroradiol 2018;39:905-09 CrossRef Medline

21. Eckard DA, Purdy PD, Bonte FJ. Temporary balloon occlusion of the carotid artery combined with brain blood flow imaging as a test to predict tolerance prior to permanent carotid sacrifice. AJNR Am J Neuroradiol 1992;13:1565-69 Medline

22. Gralla J, Schroth G, Remonda L, et al. A dedicated animal model for mechanical thrombectomy in acute stroke. AJNR Am J Neuroradiol 2006;27:1357-61 Medline

23. Burns PN, Jaffe CC. Quantitative flow measurements with Doppler ultrasound: techniques, accuracy, and limitations. Radiol Clin North Am 1985;23:641-57 Medline 